\title{
Incidence of Anemia in the Population of Dir (Lower) Khyber Pakhtunkhwa
}

\section{Imran ${ }^{1,}$, Sardar Azhar Mehmood', Wali Khan ${ }^{2}$, Shabir Ahmed', Ikram Khan ${ }^{3}$, Ahmed Zia $^{4}$}

${ }^{1}$ Department of Zoology Hazara University Mansehra, Khyber Pakhtunkhwa, Pakistan.

2 Department of Zoology University of Malakand, Dir (Lower), Khyber Pakhtunkhwa, Pakistan.

${ }^{3}$ Department of Botany Govt Degree College Samar Bagh, Dir (Lower) Khyber Pakhtunkhwa, Pakistan.

${ }^{4}$ National Insect Museum, National Agriculture Research Center Islamabad Pakistan.

Authors' Contributions

1 Data Collection \& Processing, Drafting of

Manuscript.

$2 \& 4$ Critical Review.

3 Drafting of Manuscript.

5 Data Collection \& Processing.

6 Conception \& Study design.

\section{Article info.}

Received: September 28, 2020

Accepted: April 15, 2021

Funding Source: Nil

Conflict of Interest: Nil

Cite this article: Imran, Mehmood SA, Khan W, Ahmed S, Khan I, Zia A. Incidence of Anemia in the Population of Dir (Lower) Khyber Pakhtunkhwa. RADS J Pharm Pharm Sci. 2021; 9(1):1-6.

*Address of Correspondence Author: Imrankhanuom19@gmail.com

\section{A B S TRACT}

Introduction: Iron deficiency anemia is one of the major global public health issue causes many serious diseases mostly found in the women and children of developing world.

Objective: To evaluate and assess the occurrence and disorder related to iron deficiency in the population of district Dir (Lower).

Materials and Methods: From all volunteers blood samples were collected from Vein through syringe and kept it in the EDTA tubes. Hemoglobin concentration was determined by the help of Hematology Analyzer. Following the guidelines of WHO, the value of a hemoglobin $(\mathrm{Hb})$ was $<11.5 \mathrm{gm} / \mathrm{dl}$ the cut-off for anemia. Data were analyzed by using SPSS.

Results: Overall 200 participants were examined of whom $n=80(40 \%)$ were anemic which was found higher in age 1-20 years $n=31(15.5 \%)$, farmers $n=28(14 \%)$ and house wives $n=20(10 \%)$ and malaria patients $n=7(3.5 \%)$. While in gender wise study males $n=57(28.5 \%)$ were found more anemic than females $n=23$ (11.5\%) P-value (0.95).

Conclusions: Awareness and education in public about iron deficiency anemia, its causes and related disorder can prevent anemia of iron deficiency. Knowledge about nutritional requirements and iron deficiency anemia in women can save children and whole family from many diseases like anemia. So knowledge, education and awareness in population especially in women are very necessary.

Keywords: Anemia, iron, disease, prevalence.

\section{INTRODUCTION}

Iron deficiency anemia is one of the most common nutritional problems of the globe affected $40 \%$ of the world population mostly found in children and pregnant women of the developing countries [1]. Anemia is an iron deficient blood disease due to lower concentration of hemoglobin $(\mathrm{Hb})$ than normal for each sex, age, physiological situation and altitude. [2]. Across the globe approximately $43 \%$ of the young children have iron deficient anemia and the highest rate are at age of 1 - 2 years. Although in pre-school and school going children the percentage of anemia is estimated $50 \%$ and $46 \%$ respectively [3]. In Pakistan on the prevalence of anemia no statistical data is present. However its prevalence is documented in children $61.9 \%$ and is slightly higher in non-pregnant women $50.4 \%$ than pregnant women $49.6 \%$ during National Nutritional Survey (2011) [4]. World faces numerous nutritional problems including anemia which leads to severe health problems, such 
as poor cognition, delay development and some behavioral problems [5]. Work ability, performance, body health and physical fitness are associated with parasitic infection and enrichment of iron [6]. Cancer, obesity, low dietary intake, inherited blood disease, chronic infections and chronic non-communicable diseases are also the major causes of anemia [7-8]. Many extensive adverse effects of iron deficiency anemia are infants' poor development, and poor cognitive performance in preschool and school-aged children, while loss of physical capacity, decline in work performance in young's and adults weekend immune system and enhance morbidity in all age groups [9]. Moreover, education, place of residence, breastfeeding, consumption of vegetables and fruits and pregnancy are associated with anemia [10]. Pakistan faces many nutritional and challenging diseases like anemia. It may require intake of iron rich foods in sufficient amount, attention of government, uses of balance diet on daily basis, population awareness and facilitation of population with proper nutrition and education. Low socioeconomic status, lack of health facilities and proper nutrition are the chief causes of iron deficiency anemia in Pakistan. To save population from different diseases related to iron deficiency, knowledge about iron, its importance and role in regulation and physiology of many body functions are required. The aim of this study is to explore the incidence of anemia related to iron deficiency in district Lower Dir Khyber Pakhtunkhwa Pakistan.

\section{MATERIALS AND METHODS}

\section{Study area}

Lower Dir district lies $71.8097^{\circ} \mathrm{E}$ and $34.9161^{\circ} \mathrm{N}$ its border is linked with district Swat, Dir (Upper), Bajaur, and Afghanistan on its east, south, north and west. The weather of this district is moderate. Its winter is cold and summer is hot in some areas of this district. Temperature in summer reaches to $42.5 \mathrm{C}^{0}$ and in winter its range is $-1 \mathrm{C}^{0}$ with annual rainfall from $116 \mathrm{~mm}$ to $243 \mathrm{~mm}$. Agriculture and rearing livestock is the main profession adopted by the peoples.

\section{Data collection}

The present study was carried out from July 2019 to November 2019 for the analysis of anemia in the population of Dir (Lower) Khyber Pakhtunkhwa. The total of 263 peoples were enrolled, out of these, 200 participants were contributed. The participants were at every age belonging to both the genders.

\section{Socio-economic profile of the inhabitants}

Socioeconomic status, environmental factors, comorbidities and occupation were noted. Animals rearing such as cow, buffalo, goat and sheep were in common practice. Agriculture is the main life style of the residents. Most of the residents were employed as unskilled laborers in construction sites.

\section{Collection of Blood Sample}

Venous blood was taken and carefully drawn into Potassium EDTA containing tubes. Through syringe blood samples were collected from Vein and kept it in the EDTA tubes. Each EDTA was labeled with name, age and sex. Hemoglobin concentration was determined by the help of Hematology analyzer. Following the guidelines of $\mathrm{WHO}$, the value of a hemoglobin $(\mathrm{Hb})$ was $<11.5 \mathrm{gm} / \mathrm{dl}$ the cut-off for anemia for the school going children.

\section{Data analysis}

All the data collected were analyzed by using SPSS (16 version) for require parameters. For significance of various factors, analysis by logistic regression was done.

\section{RESULTS}

In present study out of the total examined participants $(n=80 / 200) \quad 40 \%$ were found with iron deficiency anemia which was found higher in males $n=57 / 200$ $(28.5 \%)$ than females $n=23 / 200(11.5 \%)$ in gender wise evaluation (Table 1 and 5 ) (P-value 0.95). In age wise satisfaction age 1-20 years were found more anemic $n=31 / 200$ (15.5\%) followed by age 41-60 years which $n=29 / 200$ (14.5\%), age $21-40$ years $\mathrm{n}=18 / 200 \quad(9 \%)$ and age $>60$ are $\mathrm{n}=2 / 200 \quad(1 \%)$ respectively as shown in Table 2 and 5 and Figure $\mathbf{1}$ (P-value 0.38). In relation to comorbidities a total of $n=23 / 200(11.5 \%)$ were comorbid patients of whom malaria patients were found more anemic $n=7 / 200$ (3.5\%) followed by diabetics and hypertension $\mathrm{n}=6 / 200 \quad(3 \%)$ and $\mathrm{n}=6 / 200 \quad(3 \%)$ while typhoid $n=3 / 200(1.5 \%)$ and depression were $n=2 / 200(1 \%)$ respectively (Table $\mathbf{3}$ and $\mathbf{5}$ ) (P-value0.359). In association with occupation, males farmers were found more anemic $n=28 / 200$ (14\%) followed by labors $n=19 / 200$ (9.5\%), students $n=8 / 200(4 \%)$ and employees $n=2 / 200 \quad(1 \%)$ respectively while in females, house wives were found more anemic $n=$ 
Incidence of Anemia in the Population of Dir (Lower) Khyber Pakhtunkhwa

$20 / 200$ (10\%) and students $n=3 / 200 \quad(1.5 \%)$

respectively as shown in Table 4 and 5 (P-value

0.07).

Table 1. Gender Wise Distribution of the Volunteers in Study Sample.

\begin{tabular}{|c|c|c|}
\hline Gender wise & Frequency & Percentage \\
\hline Males & 137 & 68.5 \\
\hline Females & 63 & 31.5 \\
\hline
\end{tabular}

Table 2. Age Wise Distribution of the Participants in Study Sample.

\begin{tabular}{|c|c|c|}
\hline Age wise & Frequency & Percentage \\
\hline $1-20$ & 74 & 37 \\
\hline $21-40$ & 52 & 33 \\
\hline $41-60$ & 66 & 4 \\
\hline$<60$ & 8 & 26 \\
\hline
\end{tabular}

Table 3. Comorbid Diseases in the Study Sample.

\begin{tabular}{|c|c|c|}
\hline Comorbidities & Frequency & Percentage \\
\hline Typhoid & 4 & 5.5 \\
\hline Malaria & 11 & 4 \\
\hline Diabetics & 8 & 2.5 \\
\hline Depression & 5 & 7 \\
\hline Hypertension & 14 & \multicolumn{2}{|c|}{} \\
\hline
\end{tabular}

Table 4. Occupational Base Distribution in Study Sample.

\begin{tabular}{|c|c|c|}
\hline Males & Frequency & Percentage \\
\hline Student & 25 & 16.5 \\
\hline Labor & 59 & 35 \\
\hline Farmers & 71 & 43 \\
\hline Employees & 08 & 5.5 \\
\hline Female/ House wife & 48 & 24 \\
\hline Student & 13 & 6.5 \\
\hline Employees & 02 & 01 \\
\hline
\end{tabular}


Table 5. Anemia Satisfaction in Different Variables Groups.

\begin{tabular}{|c|c|c|c|}
\hline Age wise & Anemic & Non anemic & P-value \\
\hline $1-20$ & 31 & 43 & \multirow{4}{*}{0.38} \\
\hline $21-40$ & 18 & 34 & \\
\hline $41-60$ & 29 & 37 & \\
\hline$<60$ & 02 & 06 & \\
\hline \multicolumn{4}{|l|}{ Genders } \\
\hline Males & 57 & 80 & \multirow{2}{*}{0.95} \\
\hline Females & 23 & 40 & \\
\hline \multicolumn{4}{|l|}{ Comorbidities } \\
\hline Typhoid & 02 & 02 & \multirow{5}{*}{0.359} \\
\hline Malaria & 07 & 05 & \\
\hline Diabetics & 06 & 02 & \\
\hline Depression & 02 & 03 & \\
\hline Hypertension & 06 & 08 & \\
\hline \multicolumn{4}{|l|}{ Occupations } \\
\hline \multicolumn{4}{|l|}{ Males } \\
\hline Student & 08 & 17 & \multirow{7}{*}{0.07} \\
\hline Labor & 19 & 40 & \\
\hline Farmers & 28 & 43 & \\
\hline Employees & 02 & 08 & \\
\hline Female/ House wives & 20 & 28 & \\
\hline Student & 03 & 10 & \\
\hline Employees & 00 & 02 & \\
\hline
\end{tabular}

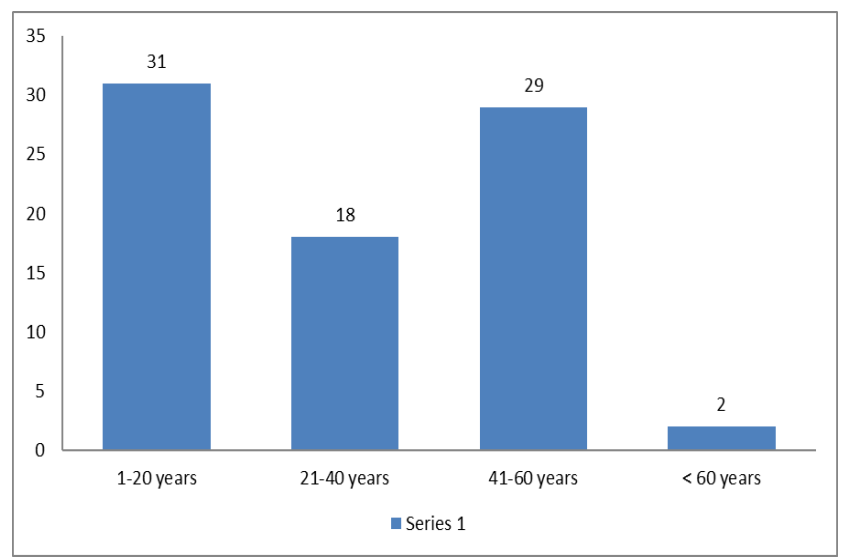

Figure 1. Shows distribution of anemia in different age groups.

\section{DISCUSSION}

Anemia is one of the public health nutritional problem of the globe which is commonly effected the population of developing countries. Iron rich foods as well as iron element in adequate amount is very essential for normal physiological function and fitness of the body. Around $40 \%$ of the world population have iron deficiency anemia which is mostly common in pregnant women and children. [1]. Iron deficiency anemia is mostly due to many infections like malaria dengue, diabetics, nutritional deficiencies, lack of proper foods, and low socio-economic status etc. Like 
other developing world Pakistan is also still facing many nutritional deficiencies issues like anemia. According to the recent National Nutritional Survey (2018) the prevalence of anemia in children is documented is $53.1 \%$ which is slightly higher in boys than girls however $56.6 \%$ of the adolescent girls and $47.7 \%$ women aged $15-49$ years were found anemic in Pakistan [11]. Present study indicates that the iron deficiency anemia is still the principle health problem in the population of Lower Dir Khyber Pakhtunkhwa, Pakistan. The research work in our country is very rare on iron deficiency anemia and risk factors regarding to some studies. The current work shows the overall prevalence of iron deficiency anemia is $\mathrm{n}=80(40 \%)$ which is higher in males $\mathrm{n}=57(28.5 \%)$ age $1-20$ years $n=31$ (15.5\%), farmers $n=28(14 \%)$, house wives $20(10 \%)$ and malarial patients $n=7$ $(3.5 \%)$ respectively. Our finding is very similar to the study conducted by Khan et al., on school going children and reported with $40 \%$ prevalence from district Swat Khyber Pakhtunkhwa Pakistan [12]. Another study conducted by Akhtar et al., and reported $39.34 \%$ prevalence of anemia from Lahore [13]. This study also strongly supported our findings. Jamali et al., reported $67.3 \%$ prevalence of anemia in female students from Dolatpur, Town Sindh [14]. Shahab et al., documented $66.8 \%$ anemia from Peshawar Pakistan [15]. In these studies the prevalence of anemia is high which may due to geographical differences or population size. $\mathrm{Naz} \mathrm{H}$. and Begum B. reported $54.3 \%$ prevalence of anemia in pregnant women from Korangi, Industrial area Karachi [16]. According to Qamar et al., $86 \%$ of pregnant women were anemic of whom $90 \%$ were house wives [17] which strongly supported our study regarding house wives. Malik et al., documented $80 \%$ of anemia from Bahawalpur Region of Pakistan [18]. However Ahmed et al., reported 44.34\% of anemia from district Multan, Punjab Pakistan [19]. According to some studies in Pakistan $69 \%$ of children $<2$ years, $47 \%$ of children $54 \%$ girls, $30 \%$ boys and $39 \%$ adolescent and $30 \%$ of females were reported to be effected by iron deficiency anemia [20-21]. Habib et al., conducted a study on adolescent girls and reported $47.9 \%$ anemia from Azad Jammu and Kashmir [22]. Iron deficiency occurs due to low intake of iron. Various foods are the best sources of iron but due to low intake not satisfying the requirements. Many factors like poverty, diseases, infections, pregnancy, and food habits are the main causes of anemia. Anemia is a principle health issue more efforts are needed to aware population from the requirements, advantages of iron with its sources. Knowledge about iron rich nutrition, supplementation, developing programs on health issues and proper diet plan to fulfill the requirement of the population is needed.

\section{CONCLUSION}

It is concluded that iron plays a vital role in our normal body function so the knowledge about iron, iron rich foods and nutrition, specific diet plan, use of healthy and alternate nutrition with proper education and knowledge in population about requirement and importance of iron and its sources are needed to save population from many diseases like anemia. Commonly women and children are more effected so awareness in women is very necessary about nutritional deficiencies and diet plan to prevent herself, her infants, children and family from anemia.

\section{Funding Source:}

Nill.

\section{Conflict of interest:}

Nill.

\section{REFERENCES}

1. Tahir MH, Bukhari MH, Gillani Z, Zafar SM. The Association of Dietary Intake and Iron Deficiency Anemia with The Socioeconomic Status in General Population of Faisalabad. Ann Punjab Med Coll. (APMC). 2017 Mar 29;11(1):63-7.

2. Idris M. Iron deficiency anaemia in moderate to severely anaemic patients. J.Ayub Med Coll Abbottabad. 2005;17(3).

3. Assefa S, Mossie A, Hamza L. Prevalence and severity of anemia among school children in Jimma Town, Southwest Ethiopia. BMC hematology. 2014 Dec;14(1):3.

4. Planning Commission. Planning and Development Division, Government of Pakistan.National Nutrition Survey 2011.

5. Grantham-McGregor S, Ani C. A review of studies on the effect of iron deficiency on cognitive development in children. Nutr.J. 2001; 131(2):649S-68S.

6. Stephenson LS, Latham MC, Adams EJ, Kinoti SN, Pertet A. Physical fitness, growth and appetite of Kenyan school boys with hookworm, Trichuris trichiura and Ascaris lumbricoides infections are 
improved four months after a single dose of albendazole. Nutr.J.1993;123(6):1036-46.

7. Cavill I, Auerbach M, Bailie GR, Barrett-Lee P, Beguin $Y$, Kaltwasser P, Littlewood T, Macdougall IC, Wilson $\mathrm{K}$. Iron and the anaemia of chronic disease: a review and strategic recommendations. Curr Med Res Opin. 2006 ;22(4):731-7.

8. Mockenhaupt FP, Rong B, Günther M, Beck S, Till $\mathrm{H}$, Kohne E, Thompson WN, Bienzle U. Anaemia in pregnant Ghanaian women: importance of malaria, iron deficiency, and haemoglobinopathies. Trans R Soc Trop. Med. Hyg. 2000 ;94(5):477-83.

9. Kapil U, Bhavna A. Adverse effects of poor micronutrient status during childhood and adolescence. Nutr Rev. 2002 ;60(suppl_5):S84-90.

10. Ali SA, Abbasi Z, Shahid B, Moin G, Hambidge $\mathrm{KM}$, Krebs NF, Westcott JE, McClure EM, Goldenberg RL, Saleem S. Prevalence and determinants of anemia among women of reproductive age in Thatta Pakistan: Findings from a cross-sectional study. Plos one. 2020; 24;15(9):e0239320.

11. Planning Commission. Planning and Development Division, Government of Pakistan.National Nutrition Survey 2018.

12. Khan F, Saeed k, Akhtar N, Zeb J, Ali H, Khan SA, Rehman HU, Shah A, Ayub A. Anemia and iron deficiency anemia in school children of district Swat, Khyber Pakhtukhwa, Pakistan. J Entomol Zool studi. 2016; 4(5): 366-368.

13. Akhtar R, Shams MU, Hanifi AN, Waheed A. Prevalence of Anaemia in Children Under 12 Years: A one year study in a Tertiary Care Hospital, Lahore. Pak J Med Health Sci. 2017 ;11(4) 1353-6.

14. Jamali $\mathrm{NH}$, Jamali $\mathrm{AA}$, Ahmer $\mathrm{A}$, Jamali $\mathrm{AA}$, Shah K, Shaikh SU, Kazi HA. Iron deficiency anemia among the female students of Dolatpur town Sindh, Pakistan. Isra Med J.2019; 11(4): 242-246.

15. Shahab F, Sikandar S, Shahab A, Raziq F. Frequency of anemia in patients presenting to tertiary care hospital in Peshawar, Pakistan. Khyber Med Univ J 2015;7(1): 30-33.

16. Naz H, Begum B. Prevalence and associated risk factors of anaemia in pregnant women in a teaching hospital, Korangi Industrial Area. Pak J Surg. 2013;29(2):131-3.

17. Qamar S, Azhar S, Murtaza G. PNS189 Iron deficiency anemia among pregnant women in Sargodha Pakistan; A qualitative study. Value Health. 2020 ;23:S318-9.

18. Malik SA, Malik MA, Malik SA. Iron deficiency anemia in Bahawalpur Region of Pakistan: A descriptive study. Pak J Med Health Sci. 2016 Jan 1;10(1):89-91.

19. Ahmed MZ, Rao T, Samad N. Prevalence of Anemia in District Multan (Pakistan): A Comparative Study. J Coll Physicians Surg Pakistan: JCPSP. 2018; 28(9):727-8.

20. Agha F, Sadaruddin A, Khan RA, Ghafoor A. Iron deficiency in adolescents. J Pak Med Assoc. 1992;42:3-5.

21. Hamedani $P$, Hashmi KZ, Manji M. Iron depletion and anaemia: Prevalence, consequences, diagnostic and therapeutic implications in a developing Pakistani population. Curr Med Res Opin. 1987;10:480-5. doi: 10. 1185/03007998709112407.

22. Habib N, Abbasi SU, Aziz W. An Analysis of Societal Determinant of Anemia among Adolescent Girls in Azad Jammu and Kashmir, Pakistan. Anemia. Hindawi. 2020; Volume 2020,1628357-9 https://doi.org/10.1155/2020/1628357. 